\title{
SISTEMAS AGROFLORESTAIS NO BIOMA CAMPOS SULINOS: UMA BREVE REVISÃO DE LITERATURA
}

\author{
AGROFORESTRY SYSTEMS IN THE CAMPOS SULINOS BIOME: A BRIEF LITERATURE REVIEW \\ Darlene Gomes da Silva ${ }^{1}$, Joyce Manieri ${ }^{1}$, Karoline Carneiro da Cunha ${ }^{1}$, Nayra Cristina Kim ${ }^{1}$, Priscila \\ Azevedo dos Santos ${ }^{1}$, Elisangela Ronconi Rodrigues ${ }^{1}$ \\ ${ }^{1}$ Faculdades Metropolitanas Unidas, São Paulo, São Paulo, Brasil, -darlenegomes934@gmail.com, \\ joycemanieri@outlook.com,ccunhakaroline@gmail.com,nayracristinakim@gmail.com, \\ pri.azevedo97@hotmail.com \& elisangela.rodrigues@fmu.br
}

\section{RESUMO}

Os sistemas agroflorestais podem ser uma alternativa para os problemas relacionados à agricultura e pecuária, aliando benefícios econômicos e sociais em prol da conservação dos biomas brasileiros. O objetivo do presente estudo é explorar as diferentes técnicas agroflorestais realizadas no bioma dos Campos Sulinos (Pampa), por meio de uma revisão bibliográfica, a partir do sítio de pesquisa Google Scholar sem período de publicação pré-definido, delineando as principais metodologias e seus resultados e enfatizando o uso das espécies nativas para a recuperação do bioma. Os estudos apresentados na região sul do Brasil evidenciam uma série de benefícios nas áreas onde houve a implantação de sistemas agroflorestais, como um ganho significante nas propriedades biológicas do solo através do aumento da matéria orgânica, da ciclagem de nutrientes e cobertura do mesmo. Além disso, os sistemas agroflorestais proporcionaram novos meios de subsistência e lucro para os produtores, mostrando que o caminho da produção sustentável utilizando as espécies nativas do bioma é possível.

PALAVRAS-CHAVE: Agrossilvicultura, Pampa, Pastagem nativa, Silvipastoril.

\section{ABSTRACT}

Agroforestry systems can be an alternative to problems related to agriculture and livestock, combining economic and social benefits in favor of the Brazilian biomes conservation. The objective of this study is to explore the different agroforestry techniques carried out in the Campos Sulinos biome (Pampa), through a bibliographic review, from the Google Scholar research site without a predefined publication period, outlining the main methodologies and their results and emphasizing the use of native species for the recovery of the biome. The studies presented in the southern region of Brazil show a series of benefits in the areas where agroforestry systems were implemented, such as a significant gain in the biological properties of the soil through the increase of organic matter, the cycling of nutrients and its coverage.

KEYWORDS: Agrosilvicultural, Pampa, Native pasture, Silvipastoral. 


\section{INTRODUÇÃO}

Os Campos Sulinos, também conhecido como região de Pampa, é um bioma presente na América do Sul que se estende por uma área de aproximadamente $750 \mathrm{mil} \mathrm{km}{ }^{2}$, compartilhada por Uruguai, Argentina e, no Brasil, no estado do Rio Grande do Sul, ocupando 63\% do Estado do Rio Grande do Sul (BRASIL, 2020). Esse bioma, caracterizado por ambientes de pradaria com predomínio de gramíneas, tem sido usado para produção pecuária por essas mesmas características. O bioma é formado por ecossistemas naturais com alta diversidade de espécies de gramíneas nativas, que constituíam a base para a pecuária do sul do Brasil antes da chegada das espécies exóticas para uso nas pastagens (PILLAR, 2009).

O uso dos Pampas para prática da pecuária precisa ser feito de maneira planejada de modo que não cause desequilíbrio ambiental, visto que o bioma possui solos arenosos, consequentemente, de alta fragilidade ambiental e muito susceptíveis à degradação (SOUTO, 1994 apud RIBASKI et al, 2005). Não obstante a isso, ao longo dos anos a visão de que os campos sulinos poderiam ser amplamente utilizados para a pecuária sem estabelecer qualquer limite, seja pelo governo ou pela sociedade custou uma degradação contínua no decorrer do tempo que devastou grande parte da vegetação característica da região. No último levantamento realizado no bioma, no ano de $2011,54,6 \%$ de sua vegetação nativa havia sido desmatada (MMA, 2017).

Existem técnicas que combinadas dentro de sistemas agrícolas podem ser utilizadas para melhorar os diversos tipos de uso do solo garantindo benefícios ambientais sem abrir mão do uso econômico, uma vez que o solo é revitalizado com o auxílio de plantas nativas e isso contribui para a geração de produtos de qualidade, aproximando esses sistemas de um modelo agrícola mais sustentável quando comparado com o modelo agrícola tradicional (PALUDO e COSTABEBER, 2012). De acordo com Balbino et al (2012), é possível criar inúmeras possibilidades de combinação no espaço e no tempo entre os componentes agrícola, animal e florestal, resultando em diferentes sistemas, conforme a classificação proposta por Nair (1993), sendo estes: silvipastoril, silviagrícola e agrossilvipastoril. No caso dos pampas, este último representa uma oportunidade para o desenvolvimento rural sustentável do bioma.

Um sistema agrossilvipastoril pode ser entendido como aquele em que integra atividades agrícolas, pecuárias e florestais, realizadas na mesma área, em cultivo consorciado e busca efeitos sinérgicos entre os componentes do sistema (NAIR, 1993). No Brasil, este sistema tem sido amplamente difundido por meio de práticas integradas de produção, que ocorrem em sucessão ou rotação, conhecidas como Integração Lavoura-pecuária-floresta (ILPF), considerado um sistema sustentável de produção agropecuária (KICHEL et al., 2014).

Entretanto, muitos estudos evidenciam que a inserção apenas de espécies exóticas nesses sistemas não contribui para a regeneração natural do bioma, sendo necessário enfatizar os estudos com espécies nativas. Conforme é citado em Pillar \& Lange (2015), a vegetação rasteira nativa difere profundamente de pastagens cultivadas, que geralmente são formadas por espécies exóticas e competem com as gramíneas nativas, alterando a estrutura florística dos ecossistemas presentes no bioma. Diante do exposto, o objetivo do presente estudo foi explorar as diferentes técnicas de produção integrada realizadas no bioma dos Campos Sulinos, por meio de uma revisão bibliográfica, delineando as principais metodologias e seus resultados e enfatizando o uso das espécies nativas para a recuperação natural do bioma.

\section{MATERIAL E MÉTODOS}

Foi realizada uma revisão bibliográfica, a partir do sítio de pesquisa Google Scholar, sem período de publicação pré-definido, considerando revistas, teses e manuais disponíveis com acesso livre sobre as técnicas agrossilvipastoris ou agrossilviculturais utilizadas no bioma Campos Sulinos, priorizando os estudos que citavam o uso de espécies nativas em sua aplicação. O estudo foi feito inicialmente com uma leitura exploratória do material selecionado e a partir disto, uma seleção de vinte trabalhos relevantes para discussão do uso de espécies nativas como forma de consórcio em sistemas de produção rural sustentável.

\section{RESULTADOS E DISCUSSÃO}

A partir do levantamento bibliográfico realizado, ficou evidente que apesar da grande diversidade de espécies com potencial econômico para consórcios agroflorestais nos Pampas, o uso dessas espécies consorciadas em sistemas produtivos não é amplamente difundido na região, mesmo com resultados promissores apontados nas pesquisas analisadas.

Com relação a sistemas não integrados, porém, utilizando diferentes espécies nativas consorciadas, Soares et al (2005) realizaram um trabalho sobre o manejo da 
pastagem nativa, com o objetivo de avaliar diferentes porcentagens de oferta de forragem ao longo do ano. A oferta de forragem (OF) é um parâmetro importante na pecuária, pois ela indica a quantidade de pasto que os animais dispõem e por isso ela é um fator determinante no desempenho da produção e no sucesso da exploração da área de pastagem. A OF é fundamental também para determinar a quantidade de peso vivo que é suportada em determinada área, para que não haja uma sobrecarga de pastagem afetando diretamente a regeneração natural do pasto, como também foi observado por Monteiro \& Poli, 2006 e Carvalho et al., 2011.

A alegação dos pecuaristas para não utilizar a pastagem natural é de que esta não oferece alta produtividade, o que, consequentemente afeta a rentabilidade (CARVALHO et al, 1998), . Entretanto, Soares et al. (2005) evidenciaram que é possível alcançar uma alta produção fazendo um manejo prévio da pastagem, concluindo que a evolução de uma menor OF na primavera, em direção a variação ascendente da OF no início do verão, tem efeito importante na redução de perdas e até na promoção de ganho no período de inverno, que é o de maior limitação na produção animal em campo nativo no sul do Brasil, devido às condições meteorológicas menos favoráveis para produção de Matéria Seca (MS).

Barcellos et al. (1980) realizaram uma pesquisa, ao longo de 11 anos, com a aplicação de adubo fosfatado em espécies nativas para verificar suas consequências no ganho de peso dos animais. As espécies de estudo foram Paspalum notatum Flüggé (grama forquilha) e Axonopus afflinis (Raddi) Kuhlm. (grama tapete). Os resultados encontrados pelos autores apontaram que houve um ganho médio diário de peso na pastagem adubada levemente superior em relação à não adubada. Porém houve uma disponibilidade maior de forragem, que resultou em maior produção por área. Além disso, o método obteve resultados duradouros, visto que 7 anos após a última adubação, o ganho de peso dos animais se manteve. Outra vantagem é que houve o aparecimento de outras espécies nativas como o Paspalum dilatatum Poir (Capim-melador) e o Trifolium polymorphium Poir (trevo), o que evidencia a regeneração da pastagem.

Com relação a sistemas silvipastoris, este remete à recuperação das funções ambientais do solo através do aumento da matéria orgânica, da ciclagem de nutrientes e cobertura do solo ofertadas pelo componente arbóreo. Lagemann et al. (2015) comprovaram que houve melhora na dinâmica nutricional do solo ao implantarem um sistema silvipastoril utilizando Parapiptadenia rigida (Benth.) Brenan (angico-vermelho) consorciada com pastagem nativa sob diferentes arranjos espaciais e adubação, para avaliar o estoque de carbono e nutrientes, sendo testadas amostras nas profundidades de $0-20 \mathrm{~cm}$ e 20-40 cm, demonstrando uma pequena tendência de maiores estoques de carbono e nutrientes nos sistemas silvipastoris quando comparados às pastagens.

Nicoletti et al. (2017) analisaram tributos químicos no solo de um sistema silvipastoril com angico-vermelho, no qual foram apresentados os resultados para os parâmetros de potássio $(\mathrm{K}+)$, alumínio trocável $\left(\mathrm{Al}^{3}+\right)$ e $\mathrm{pH}$ em diferentes profundidades e distância do tronco, com e sem adubação anual (NPK). Concluiu-se que a área adubada adquiriu maior acidificação do solo e maiores teores de $\mathrm{Al}^{3}+$. Este fato pode ter decorrido porque o crescimento vegetal associado à adubação mineral pode alterar atributos de acidez do solo, pois a acidificação do solo é influenciada pelos ciclos do Carbono e do Nitrogênio no sistema solo-planta (GOMES et al, 2008).

Porém, em relação ao $\mathrm{K}+$, houve maior concentração no solo não adubado e na superfície de maior aproximação do tronco, devido à ciclagem promovida pela árvore, pois alguns nutrientes como o $\mathrm{K}+$ tendem a se acumular no solo próximo ao tronco da árvore, em detrimento de uma depleção deste nutriente em regiões mais distantes. Além da alteração em relação à distância do tronco, a presença das árvores pode levar a absorção do nutriente de camadas de solo mais profundas em relação à pastagem (NICOLETTI et al., 2017).

Outro estudo utilizando angico-vermelho analisou a condição nutricional do plantio consorciado com pastagem nativa e foi visto que os teores nutricionais tiveram um incremento nutricional quando comparado com o campo nativo. Os teores de todos os nutrientes considerados Nitrogênio, Fósforo, Potássio, Cálcio e Magnésio - foram superiores, principalmente de nitrogênio, devido ao angico-vermelho ser uma leguminosa e consequentemente, ter uma alta fixação deste nutriente (MARTINS et al., 2018).

Em outro estudo realizado no Pampa, Nascimento et al. (2018) introduziram o sistema agroflorestal (SAF) silvipastoril baseado em combinar árvores, pastagem e gado, utilizando a Prosopis affinis Spreng (Inhanduvá) para avaliar a viabilidade econômica e financeira da espécie, nativa do bioma e que se encontra em risco de extinção. Durante a ocorrência do SAF observou-se muitos benefícios como durabilidade e qualidade da madeira que por ser de alta densidade, resistente à deterioração, fácil manejo e ter boa adaptação ao solo presente, leva a potencialização de seu uso para diversificação econômica (NASCIMENTO et al., 2018). Observando este estudo, 
verifica-se que a Inhanduvá é uma espécie adequada a ser implantada no sistema, pois apresenta características botânicas, produtivas, ecológicas e econômicas, podendo ser utilizada em vários seguimentos para obtenção de lucro, além de contribuir na alimentação dos animais.

Em uma pesquisa sobre sistemas agroflorestais implantados propriedades rurais de agricultores familiares no interior do Rio Grande do Sul, Ferreira (2014) observou o uso com sucesso de duas espécies florestais: a Leucaena leucocephala (Lam.) de Wit. (leucena), uma leguminosa perene recomendada para arborização de culturas ou de pastagens, com potencial para fornecimento de forragem para os animais (VILELA, 2009) e a Schinus terebinthifolius Raddi (aroeira vermelha) nativa do Pampa que possui crescimento relativamente rápido, alta sobrevivência e resistência a geada (BAGGIO, 1988). O autor afirma que a implantação do SAF teve como objetivo inicial a formação de barreiras contra o vento e a ornamentação do lote. No entanto, outros benefícios foram percebidos, como aumento da produção apícola, proteção de nascentes e controle da erosão (FERREIRA, 2014).

Ainda no estudo de Ferreira (2014), é apresentado uma outra propriedade que maneja três SAFs na região serrana de Pelotas-RS: um quintal agroflorestal com espécies destinadas principalmente ao consumo familiar; o cultivo de bananas em um sub-bosque de vegetação nativa e um pomar de citros com espécies nativas cujo intuito é a comercialização da madeira, principalmente a Cabralea canjerana (Vell) Mart. (canjerana). Porém, a espécie possui diversas outras indicações econômicas, como o apícola e medicinal; seus frutos possuem valor ecológico pelo alto teor nutricional para aves e pequenos mamíferos facilitando a dispersão das sementes e também produzem óleos essenciais. Ademais, é possível extrair o perfume de suas flores e o corante vermelho de sua casca (CARVALHO, 1994), havendo, portanto, diversas possibilidades de geração de renda com ganhos ecológicos quando se utiliza espécies nativas consorciadas em sistemas produtivos.

A agricultura convencional mostra-se claramente insustentável e os modelos de pecuária que exigem grandes espaços e altas quantidades de insumos não atendem ao conceito de sustentabilidade, principalmente no cenário atual de mudanças climáticas globais.

Os sistemas integrados de produção com a utilização de espécies nativas apresentam grande potencial para atender os princípios agroecológicos com base na sustentabilidade. Entre as principais justificativas para o emprego dos sistemas de integração floresta-pecuária no Sul do Brasil, podemos citar: sua utilização independe da escala de produção e pode ser adotada por pequenos, médios e grandes produtores; a escolha do modelo permite atender diferentes objetivos de produção e oferta de serviços ambientais, devido as diferentes combinações possíveis de espaçamentos e espécies a serem introduzidas; apresenta resultados em curto e médio prazo; a oportunidade de agregação de valor na propriedade e a diversificação da renda do agricultor (VARELLA \& RIBASKI, 2008; LUCAS et al., 2015).

\section{CONSIDERAÇÕES FINAIS}

Os estudos apresentados na região do Bioma evidenciam uma série de benefícios nas áreas onde houve a implantação dos sistemas que utilizaram espécies nativas, como: ganho nas propriedades biológicas do solo através do aumento da matéria orgânica, da ciclagem de nutrientes e da cobertura vegetal, incrementos de serviços ecossistêmicos nas propriedades, além de maior geração ou diversificação de renda e utilização de espécies com potencial ecológico para recuperação de áreas degradadas, principalmente pela dispersão de suas sementes, tornando-se importantes fontes de propágulos para a regeneração natural dos ecossistemas.

Evidenciar os benefícios destes estudos é de suma importância para que se haja o devido conhecimento de práticas que priorizem a conservação dos ecossistemas locais, optando sempre por espécies nativas e trazendo técnicas em prol do desenvolvimento sustentável. Considerando que o Pampas possui características propícias para a prática agropecuária, é preciso priorizar mais pesquisas e ensaios sobre a utilização das espécies nativas em detrimento as espécies exóticas, sendo possível, com isso, alcançar resultados satisfatórios a partir da vegetação nativa para produção rural.

\section{REFERÊNCIAS}

BAGGIO, A.J. Aroeira como potencial para usos múltiplos na propriedade rural. Boletim de Pesquisa Florestal, v.1, n.17, p.2532, 1988. Disponível em: https://www.embrapa.br/busca-depublicacoes/-/publicacao/282081/aroeira-como-potencial-parausos-multiplos-na-propriedade-rural

BALBINO, L.C. et al. Agricultura Sustentável por meio da integração lavoura-pecuária-floresta (iLPF). International Plant Nutrition Institute - Brasil (IPNI), n.138, p.18, 2012. Disponível em: http://ainfo.cnptia.embrapa.br/digital/bitstream/item/ 200295/1/Balbino-Agricultura-sustentavel.pdf

BARCELLOS, J.M. et al. Influência da adubação e sistema de pastejo na produção da pastagem natural. In: Pastagens, adubação e fertilidade do solo. Bagé: Embrapa, 1980. Disponível em: https://ainfo.cnptia.embrapa.br/digital/bitstream/item/ 195694/1/Barcellos-et-al-1980.pdf 
BRASIL. MINISTÉRIO DO MEIO AMBIENTE. Pampa: Conhecimentos e Descobertas. 2020. Disponível em: https://www.mma.gov.br/biomas/pampa.

CARVALHO, P.C.F. et al. Challenges and opportunities for livestock production in natural pastures: the case of Brazilian Pampa Biome. Diverse Rangelands For A Sustainable Society, p. 9-15, 2011. Disponível em: https://www.alice.cnptia.embrapa.br/bitstream/doc/907421/1/ CarvalhoEtAl.2011.pdf

CARVALHO, P.C.F. et al. Potencial produtivo do campo nativo do Rio Grande do Sul. Patiño, H.O. (ed.). suplementação de ruminantes em pastejo, p.1-20, 1998. Disponível em: http://www.ufrgs.br/gpep/documents/capitulos/Potencial\%20P rodutivo\%20do\%20campo\%20nativo.pdf

CARVALHO, P.E.R. Espécies florestais brasileiras: recomendações silviculturais, potencialidades e uso da madeira. 1.ed. Embrapa Florestas: Circular técnica, v.67, 1994. Disponível em: https://www.infoteca.cnptia.embrapa.br/infoteca/bitstream/do c/307847/1/CT0067.pdf

FERREIRA, L.R. As agroflorestas como expressões do desenvolvimento rural no rio grande do Sul: uma análise a partir da produção de novidades. 2014. 148p. (Dissertação de mestrado). Disponível em: https://lume.ufrgs.br/handle/ $\underline{10183 / 109257}$

GOMES, M.A.F. et al. Nutrientes Vegetais no Meio Ambiente: ciclos bioquímicos fertilizantes e corretivos. 2.ed. Embrapa Meio Ambiente: Documentos, v.66, 2008. Disponível em: https://www.cnpma.embrapa.br/download/documentos 66.pdf

KICHEL, A.N. et al. Sistemas de Integração Lavoura-PecuáriaFloresta (ILPF): Experiências no Brasil. Boletim de Indústria Animal. v.71, n.1, p.94,105, 2014. Disponível em: http://www.iz.sp.gov.br/pdfsbia/1401132403.pdf

LAGEMANN, M.P. et al. Estoque de carbono e nutrientes no solo em um sistema silvipastoril no bioma Pampa. Anais do VII Salão Internacional de Ensino, Pesquisa e Extensão - Universidade Federal do Pampa. p.1-2, 2015. Disponível em: http://200.132.146.161/index.php/siepe/article/view/16514

LUCAS, M.A.K. et al. Sistema Silvipastoril na Região da Campanha do Rio Grande do Sul. 1.ed. Embrapa Pecuária Sul: Documentos, v.142, 2015. Disponível em: https://core.ac.uk/download/ pdf/33888714.pdf

MARTINS, M.T. et al. Análise nutricional de um plantio monoespecífico de Parapiptadenia Rigida em campo nativo no bioma Pampa. Anais do X Salão Internacional de Ensino, Pesquisa e Extensão - Universidade Federal do Pampa. p.1-7, 2018. Disponível em: http://200.132.146.161/index.php/siepe/ article/view/39458

MMA - MINISTÉRIO DO MEIO AMBIENTE. Monitoramento do Desmatamento nos Biomas Brasileiros por Satélite (PMDBBS): Pampa 2010 - 2011. Brasília, 2017. Disponível em: https://www.mma.gov.br/images/arquivo/80049/PMDBBS/REL ATORIO\%20PMDBBS\%20PAMPA\%202010-2011.pdf
MONTEIRO, A.L.G.; POLI, C.H.E.C. A importância da oferta de forragem nos sistemas de produção de ovinos em pastagem. 2006. Disponível em: https://www.milkpoint.com.br/artigos/ producao/a-importancia-da-oferta-de-forragem-nos-sistemasde-producao-de-ovinos-em-pastagem-208n.aspx

NAIR, P.K.R. An introduction to agroforestry. Londres: Kluwer Academic Publishers, 1993.

NASCIMENTO, S.G. et al. Sistema silvipastoril na bacia hidrográfica do rio Santa Maria: uso do inhanduvá. Biodiversidade, v.17, p.130-144, 2018. Disponível em: http://periodicoscientificos.ufmt.br/ojs/index.php/biodiversidad e/article/view/7514

NICOLETTI, S.S. et al. Atributos químicos do solo em consórcio de campo natural com Parapiptadenia Rigida no bioma Pampa. Anais do IX Salão Internacional de Ensino, Pesquisa e Extensão - Universidade Federal do Pampa, 2017. Disponível em: https://periodicos.unipampa.edu.br/index.php/SIEPE/article/vie $\underline{w / 97869}$

PALUDO, R.; COSTABEBER, J.A. Sistemas agroflorestais como estratégia de desenvolvimento rural em diferentes biomas brasileiros. Revista Brasileira de Agroecologia, v.7, n.2, p.63-76, 2012. Disponível em: https://orgprints.org/22937/1/ Paludo Sistemas\%20agroflorestais.pdf

PILLAR, V.P. et al. Campos Sulinos - conservação e uso sustentável da biodiversidade. 2.ed. Brasília: MMA, 2009. Disponivel em: https://www.mma.gov.br/estruturas/chm/ arquivos/campossulinos parte1 14.pdf

PILLAR, V.P.; LANGE, O. Os campos do sul. Porto Alegre: Rede Campos Sulinos-UFRGS, 2015. Disponível em: http://ecoqua.ecologia.ufrgs.br/Camposdosul/Campos do Sul TELA.pdf

RIBASKI, J. et al. Sistemas Silvipastoris: Estratégias para o Desenvolvimento Rural Sustentável para a Metade Sul do Estado do Rio Grande do Sul. 1.ed. Embrapa Florestas: Comunicado técnico, v.150, 2005. Disponível em: http://ainfo.cnptia.embrapa.br/digital/bitstream/item/37775/1/ com-tec150.pdf

SOARES, A.B. et al. Produção animal e de forragem em pastagem nativa submetida a distintas ofertas de forragem. Ciência Rural, v.35, p.1148-1154, 2005. Disponível em: https://www.alice.cnptia.embrapa.br/bitstream/doc/222506/1/ Barcellosetal1980.pdf

VARELLA, A. C.; RIBASKI, J. Recomendações para sistemas de integração floresta-pecuária no extremo Sul do Brasil. 1.ed. Embrapa Pecuária Sul: Circular Técnica, v.35, 2008. Disponível em: https://www.infoteca.cnptia.embrapa.br/bitstream/doc/ 228686/4/CT35.pdf

VILELA, H. Série Leguminosas Tropicais - Gênero Leucaena (Leucaena leucocephala). Portal Agronomia, 2009. Disponível em: http://www.agronomia.com.br/conteudo/artigos/artigos leguminosas tropicais leucaena.htm 